\title{
Effects of Crude Oil Imparted Sand on the Durability of Concrete
}

\author{
Ajagbe W. O*, Rabiu W. A \\ Civil Engineering Department, University of Ibadan, Nigeria
}

Copyright $\mathrm{O} 2018$ by authors, all rights reserved. Authors agree that this article remains permanently open access under the terms of the Creative Commons Attribution License 4.0 International License

\begin{abstract}
A large percentage of soils in crude oil producing areas in Nigeria were contaminated to a varying degree. Past research showed reduction in the compressive strength of concrete made with crude oil impacted sand (COIS). The current effort aimed at assessing the durability of COIS concrete. Soil samples were contaminated with crude oil concentrated levels of $0,2.5 \%, 5 \%, 10 \%$ and $15 \%$ by weight of sand to produce COIS. Concrete design mix of 1:1.8:2.7 were made with COIS at the different concentrations from which concrete specimen $-100 \mathrm{~mm}$ cubes; $100 \times 200 \mathrm{~mm}$, and $75 \times 150 \mathrm{~mm}$ cylinders, were made. COIS concrete were then tested for chloride and sulphate resistance using Electrical Resistivity(ER) test on $100 \mathrm{~mm}$ x 200mm concrete cylinders and Water absorption (WA) test on 75 x $150 \mathrm{~mm}$ cylinders, respectively The COIS concrete was tested for Fire Resistance(FR) by testing the compressive strengths of heated $100 \mathrm{~mm}$ cubes. The results showed that COIS concrete exhibited an increased in durability properties as the contamination level increases. The control sample has the lowest value of ER of $119 \mathrm{kohm}-\mathrm{cm}$ which indicates low resistance to chloride ion penetration. It also has the highest value of WA of $3.9 \%$ indicating low resistance to sulphate attack. However, COIS concrete experienced reduction in strength when exposed to fire as the concentration of crude oil increases. The better durability property of the COIS concrete compliments the strength reduction.
\end{abstract}

Keywords Concrete Durability, Compressive Strength, Crude Oil, Contaminated Soil

\section{Introduction}

According to Blaszezynski[4],durability of cement concrete can be defined as its ability to resist weathering action, both physical and chemical attack i.e. resistance to corrosion, scaling, deleterious expansion, Sulphate and
Chloride attack, abrasion and other deterioration processes to which concrete may be exposed. A durable concrete is one that performs satisfactorily under anticipated exposure (working) condition during its life span (Nehdi, Pardhan[9]). Fire resistance of concrete is considered as part of its advantages over steel as construction materials. Having concrete with crude oil is susceptible to enhance the heating effect on reinforced concrete by introducing high temperature gradients and as a result of it, the surface layers tend to separate and spall off from the cooler interior (Potha.Raju[10]). The heating of reinforcement aggravates the expansion both laterally and longitudinally of the reinforcement bars resulting in loss of bond and loss of strength of reinforcement. According to BaiJ, Potha, Raju[3,10] research works have indicated that fire resistance of concrete is highly dependent on its constituent materials. Hence with COIS, the concrete contains crude oil which is a flammable liquid such that when in contact with fire, the concrete is subjected to higher heat intensity thus reducing its durability.

Over the past two decades, the amount of hydrocarbon contamination of soil and the environment has continually increased, and presently it constitutes a significant fraction of waste materials in the environment. Some major sources of hydrocarbon contamination are oil spill, leaking of petroleum from underground storage tanks, oil pipe vandalization, drilling, treatment activities for exploration and production of hydrocarbons, and hydrocarbon waste disposed from industries (Ajagbe et al[18]). Also, inadequate care on oil production operation and transportation which centered on Niger-Delta region has been mired by various degrees of environmental pollution problems including contaminated sand (Ukoli[11]).

Concrete materials contamination in the Niger/Delta region of Nigeria is caused by oil spills due to a number of reasons, including; corrosion of pipelines and tankers (accounting for $50 \%$ of all spills), sabotage (28\%), and oil production operations (21\%), with $1 \%$ of spills being accounted for by inadequate or non-functional production equipment. The largest contributor to the oil spills, total 
corrosion of pipes and tanks, is the rupturing or leaking of production infrastructures that are described as "very old and lack regular inspection and maintenance ". a reason that corrosion accounts for such a high percentage of all spills is that as a result of the small size of the oil fields in the Niger Delta, there is an extensive network of pipelines between the fields, as well as numerous small networks of flow lines- the narrow diameter pipes that carry oil from well heads to flow station- allowing many opportunities for contact with the ground since these are laid above the ground. Sabotage is performed primarily through what is known as 'bunkering', whereby the saboteur attempts to tap the pipelines, in the process of extracting sometimes the pipeline is damaged or destroyed (Ukoli [11]). Damaged lines may go unnoticed for days, and repair of the damaged pipes may takes even longer.

According to Ajagbe et al [19], 18-90\% compressive strength was lost due to $2.5-25 \%$ crude oil contamination, respectively on the effects of COIS on the compressive strength of concrete. These therefore pose the need to investigate durability of concrete made with COIS in varying concentration of crude oil. Previous research had recommended the use of COIS concrete on non-structural members and a knowledge of its durability will complement its reliability of use particularly in the affected area to reduce waste.

\section{Materials and Methods}

\subsection{Materials}

\subsubsection{Cement}

The cement used for the investigation was the Ordinary Portland Cement BS12[15] and it had the properties to act as a binding agent in the presence of water.

\subsubsection{Water}

Clean potable water was used for concreting; the water aided the hydration of cement, which resulted in setting, and hardening of the concrete BS 3148[16].

\subsubsection{Aggregates}

The coarse aggregate used had a maximum size of 10 $\mathrm{mm}$. Fine aggregate was natural sand obtained in Ibadan, Oyo state. Both the fine and coarse aggregates were spread out on neat concrete floor to dry out, so as not to influence the Concrete Resistivity and, surface absorption testing which depend on concrete components as a result of increase in water-cement ratio of the concrete (Kessler et al, Muhammed $[7,8]$. Coarse and fine aggregates conform to BS 882 [18] specification

\subsubsection{Crude Oil}

The crude oil was obtained from Bomu oil field in Gokana LGA of Rivers state, Nigeria. It has API gravity of
11.43 , specific gravity of 0.99 , density of $62 \mathrm{lbs} / \mathrm{cuft}$ and viscosity at $30 \mathrm{C}$ of 4.8 centipoise.

Other materials used for this research are $100 \mathrm{~mm}$ and 75 $\mathrm{mm}$ diameters PVC pipes, and Wenners 4-probe array which was locally fabricated.

\subsection{Methods}

\subsubsection{Preparation of Sample}

To make the Crude oil Imparted Sands (COIS), the fresh uncontaminated sand similar in grade to sands of the contaminated sites was contaminated with crude oil at $2.5 \%, 5 \%, 10 \%$, and $15 \%$. The crude oil percentages were the outcome of a research to access the level of contamination at three different locations in the polluted areas: Bomu, D-Dere and Bodo city of Gokana LGA of Cross Rivers State in Nigeria.

The fine aggregate was divided into five (5) equal parts by weight. The first part was left purely uncontaminated to represent the control sample. The second portion was weighed and crude oil corresponding to $2.5 \%$ of the weight of this portion was added as contamination to the fine aggregate. The mixture was thoroughly stirred to ensure uniformity of the mix. This procedure was repeated for $5 \%$, $10 \%$ and $15 \%$ contaminations by weight of sand and was thoroughly mixed and the resulting COIS was air-dried for about five days to allow proper reaction of the mixture and simulate the oil spill environment.

This fine aggregate contaminated with crude oil was then used to make concrete cylinders and cubes with designed mix ratio 1:1.8:2.7.

\subsection{Surface Resistivity Indication of Concrete's Ability to Resist Chloride Ion Penetration (ASTM C[1]}

The resistivity of concrete, in Ohms-cm, has been found to be related to the resistance of the specimen to chloride ion penetration. Table 1 shows these relationships.

Table 1. Chloride Ion Penetrability Based

\begin{tabular}{|c|c|c|}
\hline \multirow{2}{*}{$\begin{array}{c}\text { Chloride Ion } \\
\text { Penetrability }\end{array}$} & $\begin{array}{c}\text { Surface Resistivity Test } \\
\text { (4 inm X 200-mm } 8 \text { in.) } \\
\text { Cylinder } \\
\text { (KOhm-cm) } \\
\mathrm{a}=1.5\end{array}$ & $\begin{array}{c}150-\mathrm{mm} \text { X 300-mm } \\
\text { (6 in. X 12 in.) } \\
\text { Cylinder } \\
\text { (KOhm-cm) } \\
\mathrm{a}=1.5\end{array}$ \\
\hline High & $<12$ & $<9.5$ \\
\hline Moderate & $12-21$ & $9.5-16.5$ \\
\hline Low & $21-37$ & $16.5-29$ \\
\hline Very Low & $37-254$ & $29-199$ \\
\hline Negligible & $>254$ & $>199$ \\
\hline
\end{tabular}

$=$ Wenner probe tip spacing

Source: ASTMC[1].

\subsubsection{Sample Preparation}

Three concrete cylinder specimens' size 100 x 200mm 
were cast BS 1881:Part 108 [17] for each of the percentage contaminations in accordance with ASTM C-192 or ASTM C-31. All specimens were moist cured in accordance with ASTM-192, except as noted below, from the time of molding to testing in a moist room. The specimens were not cured in a saturated lime water tank, as this curing condition decreases the resistivity of the concrete. The specimens were allowed to cure in the molds for approximately 24 hours before removing from the molds. Immediately after demolding, four indelible marks on the top circular face of the circumference of the circle at 0 , $90,180 \& 270$ degrees were made and the marks were extended onto the longitudinal sides of the specimens. The marks served as visual aids during the resistivity readings. In order to saturate concrete cylinder with water, specimen must remain in a $100 \%$ humidity condition for at least 7 days prior to testing but the cylinders were cured for 28 days.

\subsubsection{Procedures}

i. During the test, the air temperature around the specimens was maintained in the range of 20 to $25^{\circ} \mathrm{C}\left(68\right.$ to $\left.77^{\circ} \mathrm{F}\right)$.

ii. The specimen was removed from water with excess water blot off and then transferred to the wooden holder with 0 degree mark on top.

iii. Wenner array probe were placed on the longitudinal side of the specimen at the 0 degree marks. The probe was ensured that the longitudinal centre mark was equidistant between the inner probes. All the points of the array probe were in contact with the concrete and the readings were taken after three to five seconds.

iv. Measurements of display unit were taken for both Current (I) and Voltage (V) when the number was stable on Ammeter and Voltmeter.

v. Specimen was rotated $0^{\circ}$ to 90 degree mark, and ( iii) and ( iv) above were repeated.

vi. Specimen was rotated $90^{\circ}$ to 180 degree mark, and to $90^{\circ}$ to 270 degree mark, each time repeating (iii) and (iv)

vii. The last four readings at $0^{\circ}, 90^{\circ}, 180^{\circ}$, and $270^{\circ}$ marks were repeated and Average Current (I) and Voltage (V) were calculated

viii. Resistivity was calculated using the formula: resistivity $=2 \pi \mathrm{a} \quad \mathrm{V} / \mathrm{I} \quad[1]$ (Where $\mathrm{a}=38.1 \mathrm{~mm}$, $\mathrm{V}=$ average voltage, $\mathrm{I}=$ average current).

ix. Average resistivity was calculated for the sample.

x. (iii) to $(x)$ were repeated for other specimens in the set.

Penetrability of Chloride ions depends on the results.

\subsection{Water/Initial Surface Absorption Test: ASTM C [2]}

The test for water/Initial Surface absorption of concrete was performed to determine the rate of water absorption of COIS concrete with different percentages of crude oil contamination. The results of this test were used to determine the rate of penetration of sulphate ions into the concrete for sulphate attack.

Both COIS concrete and control samples of 75 X $150 \mathrm{~mm}$ cylinder were cast and cured for 28 days, the specimens were placed in the drying oven such that each one is not less than $25 \mathrm{~mm}$ from any heating surface or from each other. The specimens were dried in the oven for 48 hours at a temperature of 100 to $110^{\circ} \mathrm{C}$. On removal from the oven, each specimen was cooled for $24 \pm 0.5 \mathrm{~h}$ in a dry airtight vessel to room temperature. Each specimen was weighed $\left(\mathrm{W}_{1}\right)$ and immediately immersed in water and at a depth such that there is $25 \mathrm{~mm}$ of water over the top of the specimen.

The specimens were left immersed in water for 24,48 and 72 hours, before being removed and dried to remove all free water from the surface.

Each specimen was then reweighed as $\mathrm{W}_{2}, \mathrm{~W}_{3}$ and $\mathrm{W}_{4}$. The measured absorption of each specimen was calculated as the increase in mass expressed as a percentage of the mass of the dry specimen.

Measured absorption $\%=\left(\mathrm{W}_{2}-\mathrm{W}_{1}\right) / \mathrm{W}_{1} \mathrm{X} 100$ [2]

The results shall be expressed to the nearest $0.1 \%$.

\subsection{Fire Resistance Test (IS:[14])}

Concrete cubes of sizes $100 \times 100 \times 100 \mathrm{~mm}$ were cast and cured in water for 28 days. The cured cubes were then placed in a heating chamber and subjected to an elevated temperature of $200^{\circ} \mathrm{C}$ for 24 hours. The specimens were allowed to cool at room temperature and tested for compressive strength. The compressive strength of the heated samples is an indication of the fire resistance of the COIS concrete.

\section{Results and Discussion}

The results are arranged into three parts for ease of presentation, analysis and discussion as follows:

\subsection{Resistance to Chloride Ion Penetration}

Results of durability testing on variation of concrete Electrical Resistivity within 28 days of curing is shown in Figure 1. 


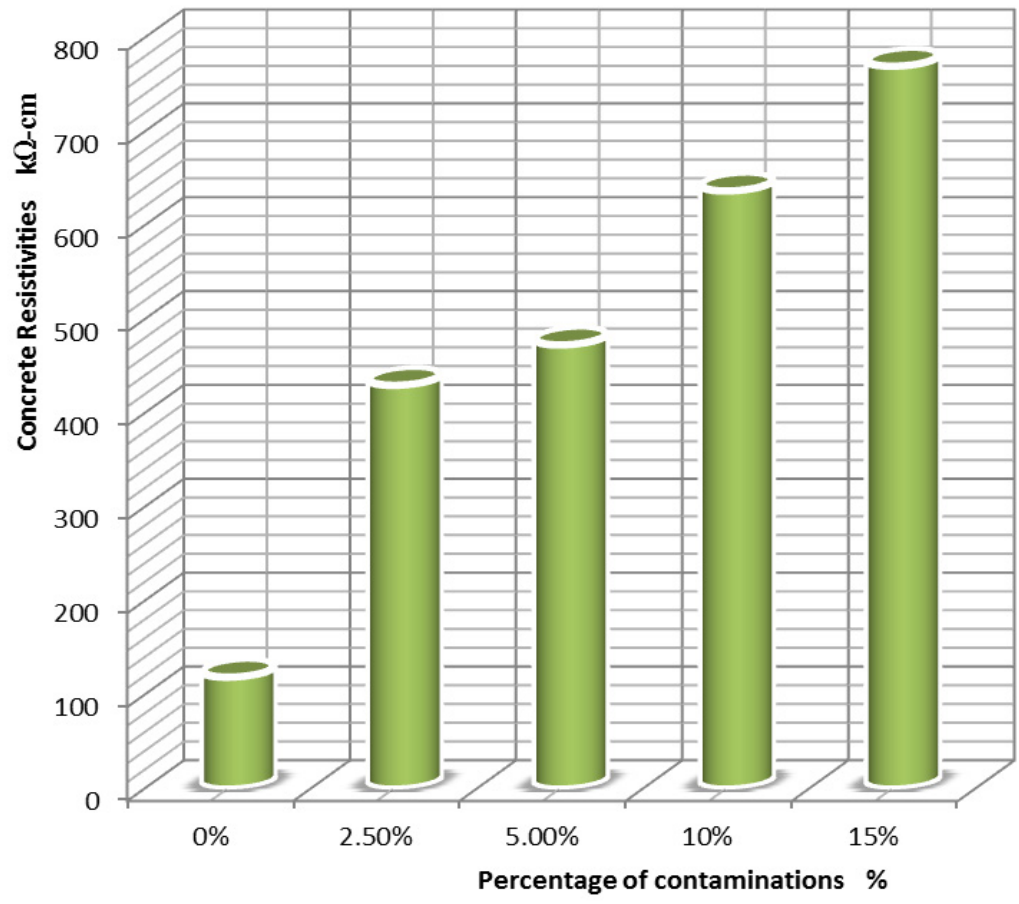

- resistivities

Figure 1. A Bar Chart showing Variations in Concrete Electric Resistivity

The COIS concrete has resistivity values ranging between 37 and $274 \mathrm{~K} \Omega$-cm compared to that of the control samples without crude oil contamination which ranged between 37 and $254 \mathrm{~K} \Omega-\mathrm{cm}$. The higher resistance on the part of the COIS concrete is an indication of better resistance to chloride ion penetration and hence higher corrosion resistance. The higher the level of crude oil contamination the better the durability of the COIS concrete.

\subsection{Resistance to Sulphate Ion Penetrability}

Results on durability testing on variation of concrete absorption capacity within 28 days of curing, 48 hours of heating, and 24, 48 and 72 hours of immersion in potable drinking water are shown in Figures 2, 3 and 4.

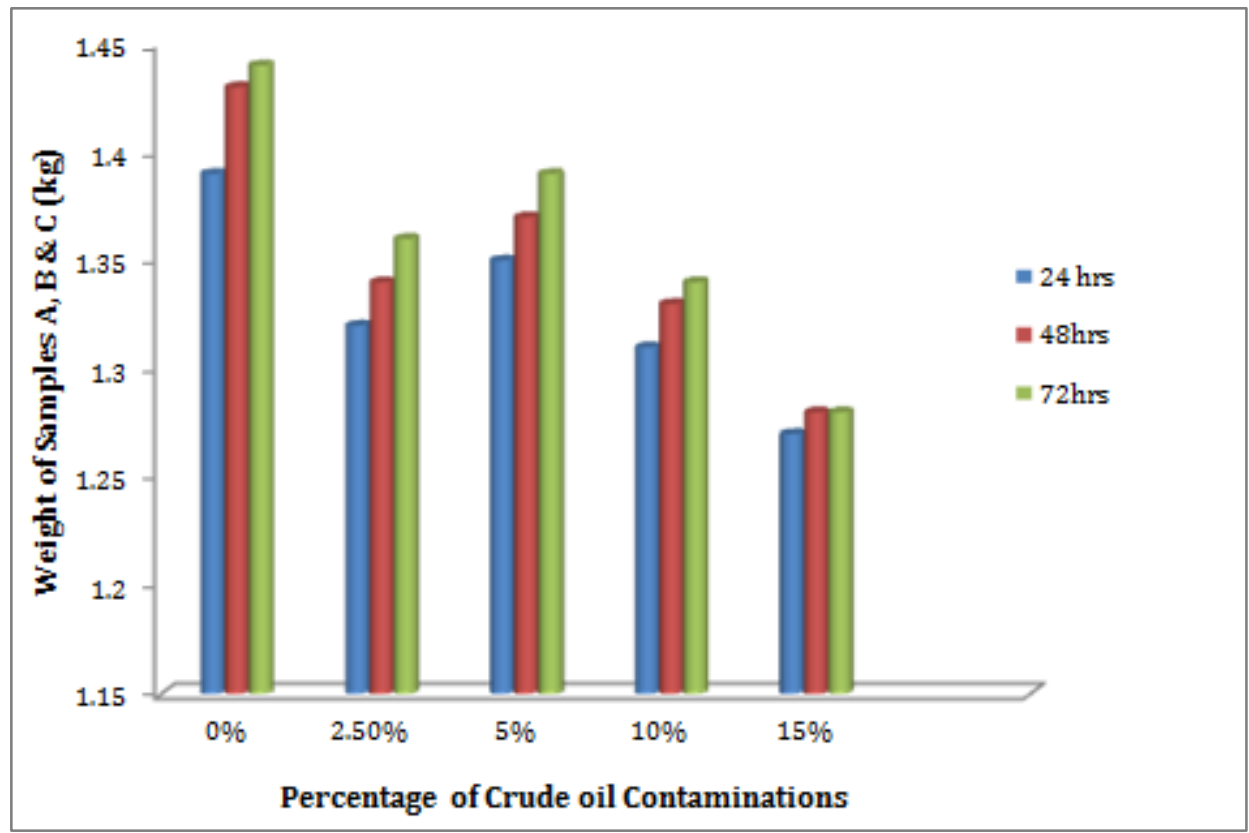

Figure 2. An Histogram Comparing Average Weights of Concretes at different hours of soaking in Water 


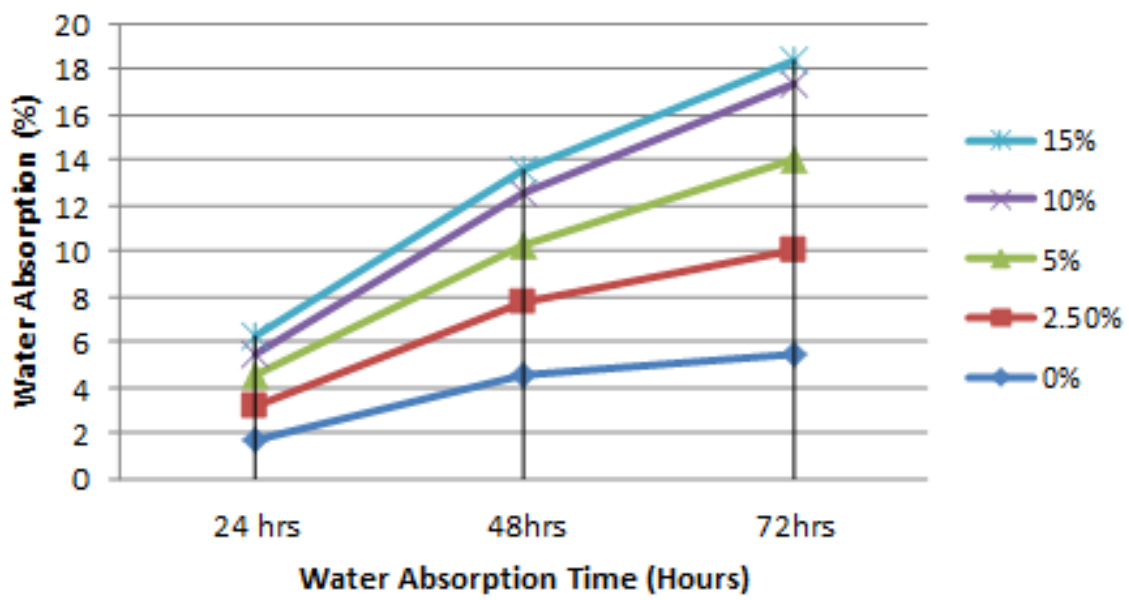

Figure 3. Graph showing Variations of Water Absorption for different $\%$ of crude oil Contaminations in concrete with time

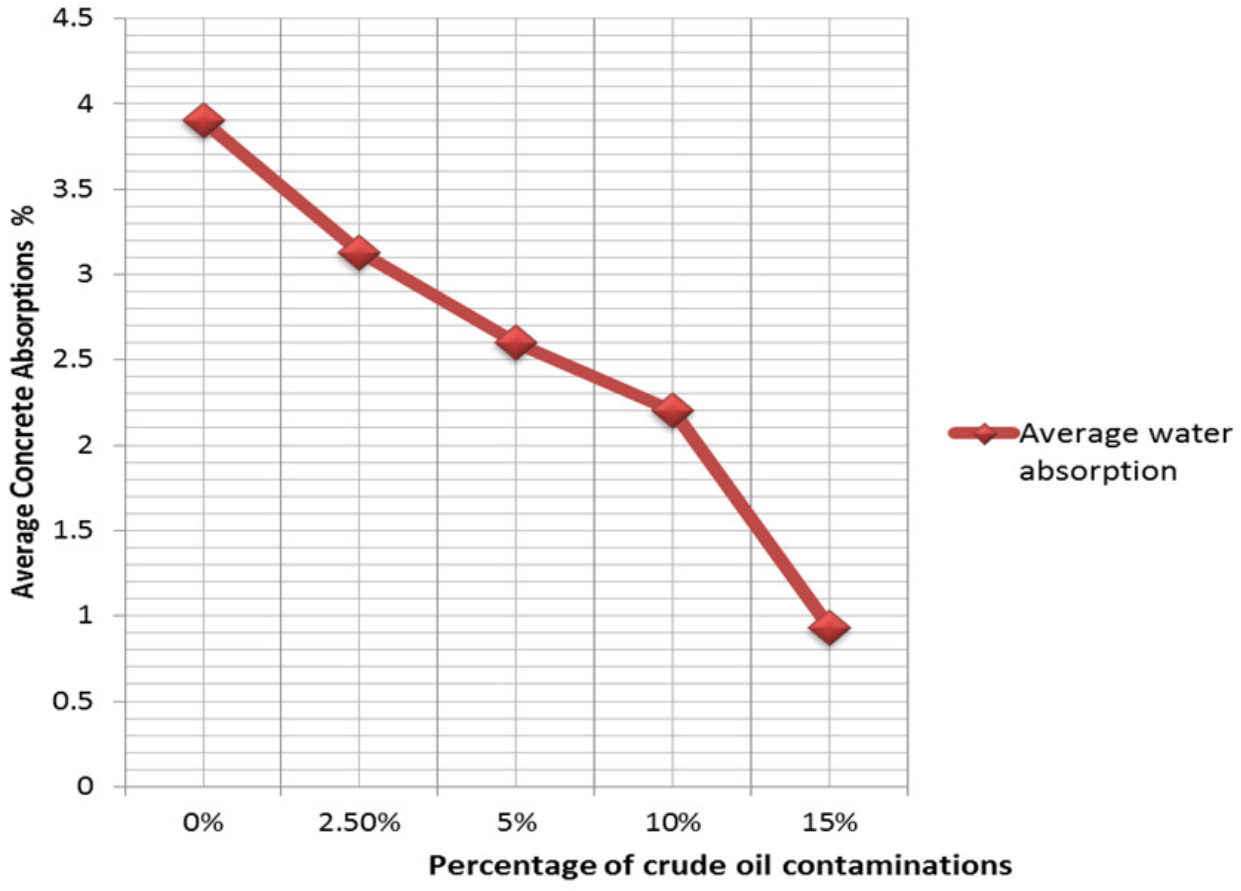

Figure 4. Graph of Concretes Average Water Absorption

The quantity of water absorbed by the samples varied proportionally with the percentage of crude oil contamination. The control specimen without crude oil contamination absorbed the highest volume of water with an average value of $3.9 \%$ and increased in weight compared to the contaminated ones, indicating that contaminated sand used in the production of concrete are likely to resist penetration of Sulphate ion better when compared with the control, thus improving the durability of COIS concrete.

Furthermore, this reduction in concrete absorption can be attributed to the fact that crude oil is an excellent repellant of water or any liquid like substances and not homogenous upon mixture with a fluid. Therefore the reaction taking place within the concrete apart from hydration or collision of crude oil molecules with water molecules, leading to the instant expel of liquid when casting is being done, which accounts for the reduction in concrete weight and compressive strength, since water is an important component for complete hydration of concrete (Zhu, Bartos[12]).

Therefore, surface coating as a result of the presence of crude oil contamination of sand used for the production of concrete, interferes with the bond between aggregate, cement paste and water. And good bond is essential to ensure a satisfactory durability and strength of concrete (Gambhir, Gupta, Amit[5,6]). But high percentage of crude oil contamination favors a more durable concrete, which shows a trend of limiting the amount of concrete absorption and surface electrical resistivity as an electrical indication of Chloride ion penetrability. 


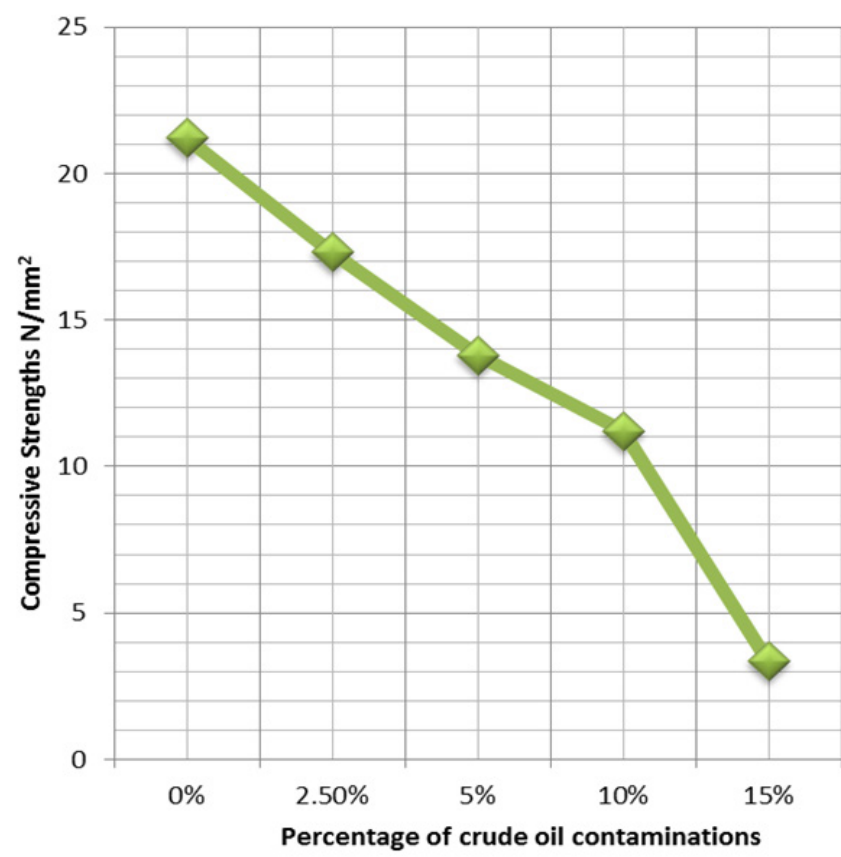

$\leadsto$ Compressive Strengths

Figure 5. Graph showing Variations of Concrete Compressive Strengths after Oven-dried

\subsection{Fire Resistance of COIS Concrete}

It was observed that the COIS concretes subjected to an elevated temperature of $200^{\circ} \mathrm{C}$ showed lower compressive strengths as compared with the control mix at the same firing temperature. Compressive strength of concrete cubes decreases as the percentage of crude oil contamination increases and the percentage of decrease in compressive strength for the $15 \%$ crude oil contamination of 3.33 $\mathrm{N} / \mathrm{mm}^{2}$ to that of control sample with $0 \%$ contamination of $21.2 \mathrm{~N} / \mathrm{mm}^{2}$ is approximately $16 \%$. The reduction in the compressive strength may be due to the fact that the crude oil which contaminated the sand changes the morphological structure of the concrete which make it less resistance to heat and temperature increase and therefore reduction in compressive strengths.

Hence, COIS concrete has a very low resistance to fire attack but depends on the percentage of its contamination that is the higher the percentage of contamination, the lower the fire resistance while uncontaminated concrete resists fire better.

\section{Conclusions}

Based on the tests and analysis carried out on the samples, the following conclusions reached are stated below:

The trend/variation in durability of COIS concrete does not behave in the same way as concrete produced with uncontaminated sand.

The research revealed that concrete made with high percentage of crude oil contamination by weight offered more resistance to water absorption and surface resistivity as an electrical indication of its permeability. That is, it resists sulphate and chloride ions penetrations into the concrete.

The presence of contaminants seems to delay or prevent the full hydration of the cement particles, by interfering with the water cement binding reactions. This contaminant being oily in nature formed an oil film around the fine aggregate and this possibly explains why water was expelled during tampering and casting. When these concrete are exposed to heat, there is reduction in compressive strength as the percentage of crude oil contamination increases.

COIS concrete can be used favorably in swampy or river enclosed areas requiring relative low compressive concrete strength.

\section{REFERENCES}

[1] ASTM C1556, (March, 2011) Apparent Chloride Diffusion Coefficient of Cementitious Mixtures by Bulk Diffusion.

[2] ASTM C642 (1996). "Standard test method for specific gravity, absorption, and voids in hardened concrete", Annual Book ofASTM Standards, Vol. 4.02: American Society for Testing and Materials, Philadelphia.

[3] Bai J, Wild S. (2002) "Investigation of the temperature change and heat evolution of mortar containing PFA and metakaolin," Cement and Concrete Composites, pg.201-209.

[4] Blaszczynski, T. Z. (2002). Reinforced Concrete Structures in Crude Oil Products Environment.

[5] Gambhir, M.L, M.L (2005) “Concrete Technology"3rd 
Edition Tata McGraw-Hill Company Limited. New Delhi Page 147-175.

[6] Gupta, B. L., Amit, G. (2004). Concrete Technology (Third Edition): Standard Publishers.

[7] Kessler, R.J., Powers, R.G., and Paredes, M.A., (2005) "Resistivity Measurements of Water Saturated Concrete as an Indicator of Permeability", Paper 05261, Corrosion 2005, NACE International.

[8] Muhammed A.H (2005), Water Absorption Test on Self Compacting Concrete exposed to different conditions.

[9] Nehdi, M. Pardhan, M., and Koshowski, S. (2004). "Durability of self-consolidating concrete incorporating high-volume replacement composite cements": Cement, and Concrete Research, Vol. 34, pp. 2103-2112.

[10] PothaRaju M, JanakiRao A (May 2001) "Effect of temperature on residual compressive strength of fly ash concrete," The Indian Concrete Journal, pp. 347

[11] Ukoli, M.K. (2001). Environmental Factors in The Management of The Oil and Gas Industry in Nigeria Posted in Web.
[12] Zhu, W. and Bartos, P.J.M. (2003). "Permeation properties of self-compacting concrete" Cement and Concrete Research, Vol. 33, pp. 921-926.Testing and Quality.

[13] IS: 10262-1980: "Recommended guide lines for mix design."

[14] IS: 519-1959: "Method of testing for concrete strength."

[15] British Standards Institution. BS 12.Specification for ordinary and rapidhardening Portland Cement, London; 1978.

[16] British Standards Institution. BS 3148.Methods of test of water for making concrete. London; 1980.

[17] British Standards Institution. BS 1881: Part 108. Method for making test cubes from fresh concrete. London; 1983.

[18] BS 882: (1983). Aggregates from Natural Sources for Concrete. London: British Standard Institution.

[19] Wasiu O. Ajagbe, Olusola S. Omokehinde, Gabriel A. Alade, Oluwole A. Agbede (2011). "Effect of Crude Oil Impacted Sand on compressive strength of concrete" Construction and Building Materials 26 (2012) 9-12 